\title{
Tres semanas de traducción en la Facultad de Filosofía y Letras
}

Del 23 de enero al 10 febrero de 2017, la Facultad de Filosofía y Letras vivió una discreta pero muy relevante serie de eventos centrados en la traducción. Primero, el Programa de Maestría y Doctorado en Letras de la UNAM, ofreció el seminario: "Translating Feminism: Exploring Theoretical and Practical Issues", impartido por la Dra. Luise von Flotow, de la Universidad de Ottawa, al que asistió buen número de estudiantes. Le siguieron otras, dentro de la Cátedra Margaret AtwoodGabrielle Roy, del Colegio de Letras Modernas de la FFyL: la presentación del libro Translating Women: Different Voices and New Horizons, compilado por von Flotow y Farzaneh Farahzad, publicado por Routledge en 2017; la presentación del sitio Meridiano 105': una e-antología de poesía de mujeres en lenguas indígenas de México y Canadá y un conversatorio sobre Translation Studies, feminismo y género.

¿Por qué hablar de traducción? ¿Por qué relacionarla con mujeres, feminismo, género, lo transnacional, lo interseccional? Porque es necesario. Porque, como quedó claro en el conjunto de actividades, la traducción es una actividad indispensable para la comunicación humana, para la construcción de mundos, la creación de lazos intersubjetivos, esparcir ideas, reforzar o socavar ideologías, ofrecer resistencia, para transgredir. Los tiempos políticos, en los cuales la era Trump es sólo la cereza del pastel, nos obligan a reflexionar sobre muchas cosas: una de ellas es la importancia de la traducción y su cruce con las necesidades sociales, políticas, económicas y culturales, donde la belleza y la articulación de palabras son actos eminentemente políticos. 
El seminario, donde se recogieron propuestas de diversos feminismos, teorías de género y queer, como manera de observar la relevancia de la traducción en la recuperación de las voces de las mujeres, fue un excelente preámbulo para el punto en el que quiero centrar esta nota: Meridiano $105^{\circ}$. Resultado del proyecto PIFFyL, encabezado por la maestra Claudia Lucotti, quien trabajó con un equipo formado por colegas de la academia y la traducción, estudiantes y poetas. Meridiano $105^{\circ}$ busca presentar y poner en contacto las voces de mujeres poetas que escriben en lenguas indígenas en México y en Canadá, de manera que, por ejemplo, un poema escrito en lengua cree pueda leerse en zapoteco y maya, y uno en purépecha, se lea en innu y cree.

Quienes traducimos y reflexionamos sobre la traducción, sabemos que esto no es poca cosa. Poner en contacto voces indígenas de dos países y muchas lenguas es una cosa, pero, que se trate de mujeres poetas y se busque el contacto entre lenguas indígenas, sin que las lenguas europeas ocupen el lugar central, es otra. No se trata solamente de hallar textos y pedir que se traduzcan: se trata de poner a dialogar voces y mundos que, en este caso, pueden necesitar varias herramientas adicionales para hacerlo. Por consiguiente, las lenguas europeas tuvieron que aparecer, pero como herramientas facilitadoras que fungieron como puente para unir las diferentes lenguas indígenas. Asimismo, hubo que buscar formatos para presentar los textos. El formato libro, por más lúdico y flexible que intentara volverse, resultó insuficiente y fue necesario acudir a los medios electrónicos para asegurar, no sólo una difusión más fácil, sino una relación entre las lenguas que trastocara jerarquías eurocéntricas. El resultado de esta titánica labor traductológica y de traducción se puede ver en http://105grados.filos.unam.mx/es/, sitio que muestra con claridad la relevancia de seguir hablando de traducción y literatura de mujeres indígenas. 


\section{Las Obras completas de Pedro Henríquez Ureña}

Desde 2015, cuando el Ministerio de Cultura de la República Dominicana publicó los últimos siete tomos de los catorce que comprenden la más reciente iniciativa de recopilación de las Obras completas de Pedro Henríquez Ureña, los estudiosos del legado del maestro dominicano cuentan con una herramienta de trabajo cuidada con esmerado rigor por Miguel D. Mena.

La labor de Mena ha sido verdaderamente hercúlea. Invirtió largos años de trabajo de sabueso literario escarbando en bibliotecas de todo el continente, contactando a los discípulos del maestro, trabajando mano a mano con doña Sonia Henríquez en el inventario de todo lo que su padre había dejado a su muerte y revisando con lupa las tres cajas de documentos del Archivo Pedro Henríquez Ureña en El Colegio de México.

El camino abierto por Juan Jacobo de Lara en 1976, con el primer intento de recoger toda la obra de Henríquez Ureña, apenas marcó un empeño que la iniciativa de 2003 por parte de la Secretaría de Estado de Cultura no pudo mejorar. La de Mena es ciertamente la más exhaustiva tarea de recopilación. A esto hay que agregar su encomiable labor en cuanto al establecimiento de los textos. En efecto, Mena no sólo reunió todo lo conocido del maestro, sino que cotejó línea por línea las diferentes versiones de los textos que Henríquez Ureña había dado a la imprenta. Las variantes que el gran humanista introdujo en sus escritos fueron recurrentes; Mena las identifica todas, incluso las que Henríquez Ureña realizó de su puño y letra en los manuscritos que se conservan en El Colegio de México. Se trata de un recurso invaluable tanto para el especialista como para el lector curioso por conocer la manera en que funcionaba el taller del filólogo. 
Entre los aspectos más notables de estas Obras completas hay que subrayar la inclusión de En la orilla: gustos y colores, uno de los numerosos hallazgos de Mena al examinar el archivo personal de Pedro Henríquez Ureña. De esta curiosa colección de textos del dominicano, en su mayoría en clave aforística, se tenía noticias por las menciones en su epistolario y la publicación de algunos fragmentos en la compilación de Lara. Mena rastrea estos detalles al tiempo que señala las partes del libro que nunca llegaron a imprenta.

Otros aportes importantes por su rareza y valor bibliográfico son el hallazgo de una conferencia sobre Gilbert Keith Chesterton de 1936, la recopilación de todas las colaboraciones de Henríquez Ureña en la revista Sur, así como múltiples declaraciones y textos de saludo, homenaje y agradecimiento hallados en el archivo personal del maestro.

A pesar de la importancia de la aparición de las Obras completas de Pedro Henríquez Ureña, este acontecimiento no ha sido saludado por ninguno de los especialistas dominicanos; es más, los comentaristas actuales de la obra del gran humanista en su país de origen ni siquiera citan a partir de este archivo, sino que recurren a lo recogido por Juan Jacobo de Lara en los años setenta. En un momento en que los estudios en torno al sabio dominicano, tan caro a la historia intelectual del México moderno, demuestran un renovado interés en su legado, justo es celebrar el resultado de un esfuerzo como el de Miguel D. Mena.

El legado de Pedro Henríquez Ureña está aún lejos de poder considerarse identificado a cabalidad. Hay todavía considerables lagunas, sobre todo en lo tocante a su epistolario de los años argentinos, que sólo podrán cubrirse cuando ciertos potentados del mundo intelectual dominicano empiecen a mostrar magnanimidad compartiendo los tesoros que esconden en sus bibliotecas.

NÉSTOR E. RODRÍGUEZ 


\section{Imágenes para ver-te. Una exhibición del racismo en México. Exhibir el racismo en México. Notas acerca de una exposición}

El racismo ha sido y es uno de los más graves problemas que ha sufrido la humanidad en los últimos dos siglos. La división de los seres humanos en razas, unas consideradas mejores que otras, generó una manera de mirar, de explicar las diferencias físicas y culturales que existen entre los distintos pueblos del planeta; fue la base científica sobre la cual los europeos construyeron sus imperios, dominando los demás continentes, estableciendo diferentes formas de control basadas igualmente en teorías que proponían la necesaria civilización de los pueblos considerados salvajes.

En varios países de Latinoamérica, Asia y África tuvieron lugar procesos de colonización internos, esto es, impulsados por las élites locales que se pensaban europeos, de raza blanca. Fue el caso de México, donde los criollos veían a la población indígena como un obstáculo al progreso de la nueva nación tras la Independencia, al mismo tiempo sepultaban en el olvido a la población de origen africano y asiático, todo ello a pesar de la proclamación de la absoluta igualdad de todos los habitantes del país y de la abolición de la esclavitud. Fue justamente en el siglo XIX cuando, bajo el concepto de raza, se generó una serie de clichés sobre los pueblos indígenas, convirtiendo su físico y modo de vida en rasgos de inferioridad, lo cual prevalece hasta nuestros días, permeando todas las representaciones que de ellos se hace, desde los libros de texto hasta la publicidad, pasando por el arte y la ciencia.

Poco afectó la Revolución estas imágenes, casi nada modificó tales juicios, pues el supuesto mestizaje terminó por ser un manto que ocultó 
el racismo existente en las políticas públicas, en la educación y en el paternalismo que se implantó bajo el lema de la "redención del indio" (los textos de Manuel Gamio y José Vasconcelos dan cuenta de tal discurso). El resultado es que vivimos todavía en una sociedad impregnada de racismo hacia los indígenas, entre un discurso que los compadece y acciones que los nulifican como personas, como sujetos sociales organizados de una manera distinta, con formas de vida y creencias que difieren de las llamadas mestizas.

¿Cómo abordar este problema en una exposición en un museo? Nada sencillo, hay muchos escollos. Hay una relativización extrema, al afirmar que el racismo es propio del ser humano, que existe desde siempre, que en México hay racismo contra los blancos, etc.; una banalización, al querer contrarrestarlo con un discurso cientificista que sostiene que no hay racismo ya que no existen las razas humanas, y tapiza muros enteros con rostros que dan cuenta de la diversidad humana, propia de la sociedad post-racial que tal posición anuncia, una estética cercana a la de Benetton; el discurso trágico de los grandes genocidios, que centra el racismo en tales hechos, dejando de lado lo actual, lo que cotidianamente acontece en el mundo contemporáneo; y otras tantas posiciones más, que dificultan lograr cierta claridad.

La exposición Imágenes para ver-te. Una exhibición del racismo en México, presentada en el Museo de la Ciudad de México del 16 de mayo al 19 de octubre de 2016, de la cual fui curador, tuvo como propósito central exhibir el racismo existente en la sociedad mexicana, en la ciencia y la cultura de nuestro país, en el imaginario nacional. Con base en los clichés generados a lo largo del tiempo sobre los indígenas - que cristalizaron en los estudios científicos del siglo XIX - , fueron considerados como imágenes, se organizaron núcleos temáticos que permitieron establecer un discurso visual en el espacio, donde las imágenes de la ciencia entran en relación con las del arte, con documentos de distintas épocas y con una serie de obras contemporáneas creadas exprofeso con el propósito de articular el discurso, funcionando en el espacio a manera de atractores. Textos de sala breves pero contundentes y cédulas sencillas.

El recorrido iniciaba con una breve sensibilización y un primer punto sobre el racismo en Estados Unidos, identificado de manera general 
como paradigmático, para luego pasar a una sala introductoria donde se trata la esclavitud en México, la clasificación de las razas y la arbitrariedad que siempre encierra cualquiera de ellas. Después, se entraba al núcleo temático "El rostro", la primera y más distintiva impresión que de cualquier persona se puede tener, con todas las teorías que se desarrollaron alrededor de éste, incluida la mirada estética; seguía "El color", lleno de tantas connotaciones y central en el racismo. La sala de "Identidad y mestizaje" se imbricaba con la de "El cuerpo", ya que confluyen en la idea del enaltecimiento del indígena antiguo: glorioso, y el contemporáneo: degenerado, destinado a desaparecer, a fundirse en la nación mestiza.

Por último, tres núcleos funcionaban a manera de línea en el tiempo ("El orden colonial”, "El orden decimonónico" y "El orden contemporáneo") con el fin de apreciar cómo entran en acción los núcleos temáticos con las relaciones que se han establecido entre la élite, que siempre dice representar a la nación, y los pueblos indígenas y sus descendientes urbanos, no considerados como tales, porque ya no hablan la lengua propia, nombrados con muy diversos epítetos, pero siempre asociados a lo indio, parecidos a..., como..., con cara de... Las categorías que operaron en cada época son distintas, como lo son también los espacios (el siglo XIX es eminentemente rural y en él ocurre el gran despojo y una severa disminución de la población indígena), las clasificaciones que resultan varían, al igual que los nombres empleados para designar a los distintos grupos humanos y la aceptación abierta de la discriminación hacia negros e indígenas. Queda claro que el racismo no es un asunto del pasado.

Finalmente, a manera de epílogo, una instalación sirve para vernos y pensarnos, para mirar al otro de una manera distinta, una invitación a continuar la reflexión sobre el racismo que vivimos, a imaginar formas de atajarlo; como colofón, remata con una frase de Wittgenstein: "Todo lo que vemos podría ser de otra manera".

Los comentarios en el cuaderno dispuesto al final del recorrido son un aliciente para proseguir con este trabajo. Llevaremos la exposición a Oaxaca, al Centro de las Artes de San Agustín (CASA), en noviembre de 2017. Quien no haya podido ir al Museo de la Ciudad de México 
y se le dificulte visitar Oaxaca, puede darse una buena idea de ella en el sitio: www.exhibirelracismo.mx. Dejen sus comentarios; siempre se agradecen.

CÉSAR CARrillo TRUeba 